\title{
ABSTRACTS FROM THE SCIENTIFIC AND TECHNICAL PRESS.
}

\section{Issued by the}

Directorates of Scientific Research and Technical Development, Air Ministry. (Prepared by R.T.P.)

No. 67. MAY, 1939.

The Air Power of Germany. (M. Muratori, Inter. Avia., No. 633-4, I 2/4/39, pp. I-3.) (67/1 Italy.)

According to Italian sources, the first line strength of the German Air Force amounted to 3,000 machines in June, 1938 .

The principal types then in use are given in the following table:-

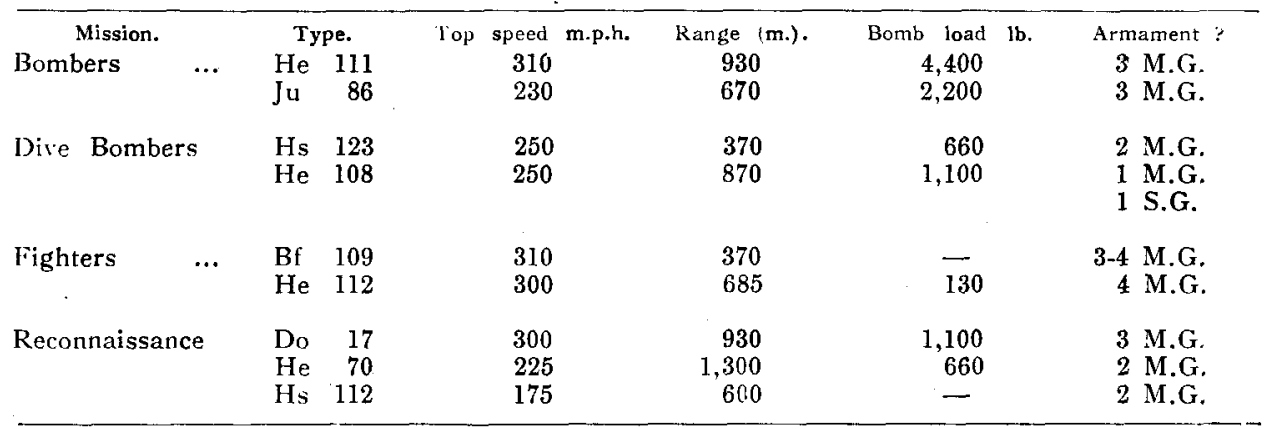

In April, 1939, the first line strength had been doubled (6,000 machines), new types replacing at the same time some obsolescent machines.

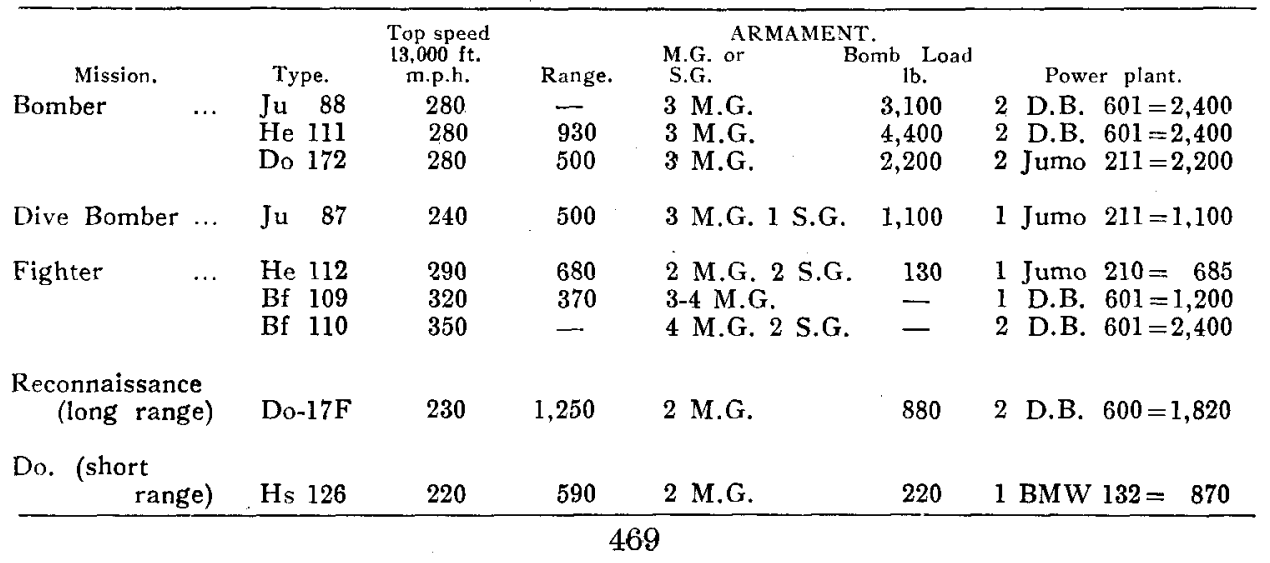


Outstanding types in the above table are the Ju 88 , credited with a considerably higher speed than $280 \mathrm{~m} . \mathrm{p} . \mathrm{h}$. and the twin-engined fighter Bf $\mathrm{I} 1 \mathrm{O}$.

The almost exclusive employment of D.B. and Jumo engines should be noted.

Of the total first line strength, 3,000 machines are bombers, 2,000 fighters and $1, \infty 0$ reconnaissance aircraft.

\section{Emergency Repairs of Fractured Gas and Water Mains (A.R.P.). (Enginecring,} Vol. I 47, No. 3821, 7/4/39, p. 4I0.) (67/2 Great Britain.)

The connection to the broken main is made by a sleeve. This is slipped over the fractured end which may, if necessary, be roughly squared with a hammer, and is held firmly in place by set-screws disposed radially. The seal is made by a heavy rubber ring, held in place by a ring not unlike an inverted gland, and tightened up by bolts. Attached to the sleeve by a Victualic joint is a reducing piece to which bends and pipes are coupled.' It will be clear that the sleeve must conform to the external diameter of the main concerned which means that the undertaking would have to stock it, complete with reducers, in sizes determined by its mains. The bridging pipes and bends, being of standard sizes, may be stocked as may be considered necessary; it is possible, for instance, that only one bore of pipes and bends would be needed.

Method of Observation for Artillery. (Rev. de l'Arm. de l'Air, No. I14, Jan.Feb., r939, pp. 83-85.) (67/3 Germany.)

There are two main types of artillery targets :-

(1) Enemy batteries.

(2) Troops.

In either case observation by aircraft has been of the greatest use in the past. Modern A.A. artillery may however force the observation plane to remain well behind the first line $(4 \mathrm{~km}$.). This requires special low speed aircraft to enable the observer to use binoculars of high magnification, whilst flying in a circle. Even then the oblique view is unsatisfactory and the author gives a list of alternative methods of observation in order of distance of observer from the front line :-

(I) $20 \mathrm{~m}$. ladder.

(2) Trench mortar projecting camera attached to parachute (altitude several hundred meters).

(3) Small balloon or captive helicopter carrying camera $(1,000 \mathrm{~m}$.).

(4) Free flying helicopter with observer $(2,000 \mathrm{~m}$.).

(5) Normal observation aircraft (up to $5,000 \mathrm{~m}$.).

(6) Motorised observation balloon, filled with helium (I,500 m.).

(7) Normal observation balloon, filled with hydrogen $(2, \infty 00 \mathrm{~m}$.$) .$

(r), (2) and (3) would operate within I $\mathrm{km}$. of the front line, (4) at $3 \mathrm{~km}$., whilst (6) and $(7)$ are generally placed well to the rear $(5.5$ and $7.5 \mathrm{~km}$. respectively).

In addition the author refers to the possibility of small wireless controlled aircraft for taking photographs from an altitude of about $1,500 \mathrm{~m}$. at an average distance of $2 \mathrm{~km}$. from the front line.

Fire at Mancuvring Aircraft. (G. A. Chester, Coast Artillery Journal, Vol. 82, No. 2, March-April, I939, pp. I I 4-1 25.) (67/4 U.S.A.)

I. There are certain definite limits of manœuvre, set by the aerodynamic and structural design of the aeroplane, and wholly independent of the desire or skill of the pilot. The existence of these limits simplifies the problem of firing against manœuvring aircraft and knowledge of these limits is of great value to a manœuvring adjusting officer attempting to fire effectively on a manœuvring target. 
2. Bombsights are likely to appear in the near future that will make it practical to bomb from a steady glide. Present directors are not designed to fire automatically on gliding targets; and firing effectively with present directors requires a specialised technique and organisation.

3. Under zigzag, repetitive mancuvres (of which the $S$ curve is an example) it may be desirable to have the trackers average the course by eye and fire down its centre.

4. Artificial dispersion is desirable when firing on certain types of manœuvres. Most manœuvres can be countered by one of four burst patterns, and some means of producing these burst patterns is desirable.

The Technique of Building Demolition. (G. Loesch, Z.V.D.I., Vol. 83, No. 18, 22nd April, 1939, pp. 457-762.) (67/5 Germany.)

After considering the more usual methods of demolition (pick-axe and pneumatic drill) the author deals with the utilisation of explosives. This new method has been used extensively in recent reconstruction work in Berlin. In the case of ferro-concrete building, high explosives cause the concrete to part from the steel frame and the building can be caused to collapse in stages without danger to the neighbourhood. Foundations are best destroyed by using liquid oxygen as an explosive. This method has been developed by Wiethuchter and consists of a combination of carbon and liquid oxygen, the mixture being fired by means of a thermite primer. The explosion is local and there is very little splinter action.

Constructional Work on Air Raid Shelters and Other Protective Work. (R. W. G. Clarke, J. Inst. Civ. Eng., Vol. I I, No. 6, April, I939, pp. 573-84.) (67/6 Great Britain.)

The works described have either been constructed or are under construction and are applicable to a wide variety of site and other conditions. Whilst not exhaustive, they represent the application of Home Office and other A.R.P. recommendations.

Protection from direct hits from high explosive bombs do not come under consideration.

The works cover:-

1. Protection of personnel from:-

(a) Gas and incendiary bombs.

- (b) Light explosive bombs.

(c) Impact and penetration from $(a)$ and $(b)$.

(d) Blast and fragmentation.

(e) Demolition.

(f) Concussion.

2. Protection of power plant from :-

(a) Incendiary bombs.

(b) Light explosive bombs.

(c) Impact and penetration from (a).

(d) Blast and fragmentation.

On a capacity basis the shelters cost from $£ 8$ to $\mathcal{E}_{\mathrm{S}}$ io per head. This figure compares very favourably with trench-type shelters, the costs of which run as follows :-

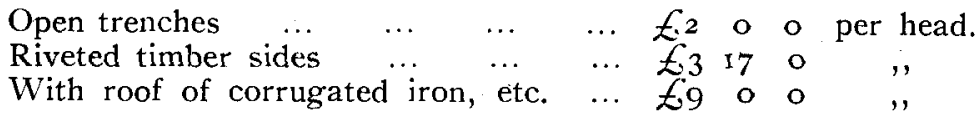

Development Trends in the Design of Fighter Aircraft. (Inter. Avia., No. 642, 9th May, 1939, pp. 1-4.) (67/7 Switzerland.)

The present day standard type single-seat fighter will maintain itself in the inmediate future with increased engine power and speed improvements of up to 
at least 435 m.p.h. Its development, however, may be assumed to result in the transfer of the engine to the centre of gravity, eventually with the use of counter-revolving airscrews (once the problem of controllability has been solved). Furthermore, an improvement in the landing gear may be anticipated, probably by the changeover to the nose-wheel design. Concurrently, the development of the twin-engined single-seat fighter and multi-seat fighter will doubtlessly make lurther progress and speeds equalling those of the single-engined single-seat fighter may be expected.

Turbulence and Diffusion. (H. L. Dryden, Ind. and Eng. Chem. (Industrial Edition), Vol. 31, No. 4, April, 1939, pp. 416-425.) (67/8 U.S.A.)

Modern developments in the experimental and theoretical aspects of turbulence in relation to the process of diffusion are reviewed. The concept of isotropic turbulence, its description in terms of the statistical properties designated " intensity and scale," and its experimental realisation are discussed at some length. Taylor's theory of diffusion by continuous movements is described and illustrated by his application of the theory to the diffusion of heat from a line source in an air stream with isotropic turbulence. At distances downstream which are small in comparison with the scale of turbulence, the diffusion depends only on the intensity of the turbulence; at large distances, the scale of the turbulence is also an important factor.

Reynolds' description of non-isotropic turbulence is given in terms of mean values of products of fluctuations of the velocity components and of the methods now available for measuring these mean values in two-dimensional flow. Von Kármán's description of the scale characteristics of non-isotropic turbulence in terms of correlation tensors is briefly stated.

Recent results on the mixing of jets with the surrounding air are briefly reviewed, and the essential difference between diffusion of momentum and diffusion of heat or matter (smoke, dye) is pointed out, namely, that the diffusion of momentum is affected by pressure gradients whereas no corresponding factor occurs in the diffusion of heat or matter. Hence the parallel between skin friction and heat transfer is invalid except in special cases.

The practical means of securing large turbulence to promote rapid mixing is discussed as applied to continuous processing, namely, by turbulent flow in a pipe, by jets emerging in quiescent air or in a counter current, and by turbulence in the wake of obstacles.

Fluid Resistance in Pipes. (M. P. O'Brien, R. G. Folson and F. Jonassen, Ind. and Eng. Chem. (Industrial Edition), Vol. 31, No. 4, April, 1939, pp. $477-81$.$) (67/9 U.S.A.)$

Formulæ based on the theory of fully developed turbulent flow and on experiments using artificially roughened pipes are applied to extrapolated data for commercial pipes in order to obtain the equivalent roughness. Using this roughness, it is found that clean pipes do not follow a curve similar to that of Nikuradse in the transition zone between rough and smooth flow conditions. The conclusion is drawn that the turbulence theory has not yet provided a reliable generalised treatment of pipe resistance in the region important in engineering problems.

Eddy Diffusion. (W. L. Towle and T.. K. Sherwood, Ind. and Eng. Chem. (Industrial Edition), Vol. 3I, No. 4, April, I939, pp. 457-62.) (67/10 U.S.A.)

Diffusion experiments were carried out at points 60 to 70 diameters downstream from the inlet ends of two ducts, 30.5 and $15.24 \mathrm{~cm}$. in diameter, with air in turbulent flow at Reynolds numbers from I 2,000 to 180,000 . Carbon dioxide and hydrogen were introduced at the axis of the duct, and concentration 
traverses over the central third of the duct diameter were obtained at points up to 4 metres downstream. The results were interpreted in terms of the calculated values of the eddy conductivity, $E$, obtained by comparing the data with an adaptation of the Wilson equation for heat dissipation from a continuous point heat source in a moving stream. The values of $E$ obtained were of the order of roo times the molecular diffusivity, and were the same for hydrogen as for carbon dioxide. $E$ was found to approach an asymptote with increase in distance between injector tube and sampling traverse. The asymptotic values of $E$ increased approximately proportionally to increase in Reynolds number.

Effect of a Screen Grid on the Turbulence of an Air Stream. (W. L. Towle, T. K. Sherwood and L. A. Seder, Ind. and Eng. Chem. (Industrial Edition), Vol. 31, No. 4, April, 1939, pp. 462-3.) (67/r I U.S.A.)

The technique previously developed for measuring diffusion in a turbulent gas stream was employed to study the turbulence conditions downstream from a wire screen grid in a $30.5 \mathrm{~cm}$. duct. The eddy diffusivity, $E$, was obtained in the region from 0.5 to 62.5 duct diameters downstream from the grid. In the first I5 diameters downstream, $E$ was less than half the value obtained with no grid present, but increased to approach an asymptote at about 45 diameters downstream. The asymptotic value was approximately equal to that obtained at the same Reynolds number with no grid.

Summary of N.A.C.A. Investigations of High Lift Devices. (C. J. Wezinger, J.S.A.E., Vol. 44, No. 4: April, 1939, Transactions, pp. 161-72.) (67/12 U.S.A.)

Various basic arrangements of high-lift flaps investigated by the N.A.C.A. are grouped for comparison. The comparisons made in this figure are of the wing section, or infinite aspect ratio characteristics, corresponding to an effective Reynolds number of $3,500,000$. The characteristics considered are the maximum lift coefficient, the increment of maximum lift coefficient due to the lift-increasing device and the ratio of maximum lift to minimum drag which is an indication of the speed range obtainable with a given combination.

The slotted types of flap appear to be the most promising on the basis of the aerodynamic characteristics listed; the N.A.C.A. arrangement of the doubleslotted flap (unpublished) shows up the most favourable of the entire group.

With supplementary equipment, several investigations have been made in the wind tunnel of model wings on which the boundary layer has been controlled by an external blower connected to the wing. These test results and other results from unpublished data indicate that, in general, lift coefficients of over 3.0 at large angles of attack could be obtained experimentally with relative small power required for the blower. Data available at the present time are believed to be insufficient for application to designs incorporating the foregoing types of boundary layer control methods. ( $5^{2}$ references.)

Some Phases of Wind Tunnel Work. (H. L. Dryden, J.S.A.E., Vol. 44, No. 4, April, 1939, p. 22.) (67/1 3 U.S.A.)

Starting with a brief description of early wind tunnels, the author mentions discrepancies observed in measured drag coefficients of sphere, and describes briefly Prandtl's classical explanation of the phenomenon. Modern methods of measuring the intensity and scale of wind tunnel turbulence, and the correlation of these two into a single turbulence parameter as suggested by G. I. Taylor are next discussed. The relation of critical Reynolds number of spheres to this parameter as determined in a number of wind tunnels is shown, and the significance of these results in indicating the very low turbulence existing in free air is pointed out. The general trend of wind tunnels is towards lower turbulence 
and the significance of this trend in leading to improved understanding and prediction of aerodynamic characteristics in flight is discussed.

In conclusion, the author exhibits the classical laminar and turbulence skin friction curves, and points out the significance of the transition point in practical aerodynamic problems.

\section{Determination of Boundary Layer Transition on Three Symmetrical Aerofoils in} the N.A.C.A. Full-Scale Wind Tunnel. (A. Silverstein and J. V. Becker, N.A.C.A. Report No. 637, 1939.) (67/14 U.S.A.)

For the purpose of studying the transition from laminar to turbulent flow, boundary layer measurements were made in the N.A.C.A. full-scale wind tunnel on three symmetrical aerofoils of N.A.C.A. ooog, 0oI 2 and 0018 sections.

The results indicate no unique value of Reynolds number for the transition, whether the Reynolds number is based upon the distance along the chord or upon the thickness of the boundary layer at the transition point. In general, the transition is not abrupt and occurs in a region that varies in length as a function of the test conditions. With increasing lift, the transition on the upper surface moves toward the forward stagnation point; whereas, on the lower surface, the transition progresses in the opposite direction. This effect is most marked for the thin aerofoils. The total head tubes and hot wires indicate essentially the same point of transition. Profile drag results are given and a correlation of the drag and the transition measurements is attempted.

The Compressibility Burble and the Effect of Compressibility on Pressures and Forces Acting on an Aerofoil. (J. Stack, W. F. Lindsey and R. E. Littell, N.A.C.A. Report No. 646, 1939.) (67/15 U.S.A.)

Simultaneous airflow photographs and pressure distribution measurements were made of the N.A.C.A. 44,12 aerofoil at high speeds to determine the physical nature of the compressibility burble. The tests were conducted in the N.A.C.A. 24-inch high speed wind tunnel.

The data presented include the results of pressure distribution measurements and force tests for three low angles of attack for a speed range extending from one-tenth the speed of sound to speeds in excess of the critical values at which a breakdown of the flow, or compressibility burble, occurs.

The results show the general nature of the phenomenon known as the compressibility burble. The source of the increased drag is shown to be a compression shock that occurs on the aerofoil as its speed approaches the speed of sound. Finally, it is indicated that considerable experimentation is needed in order to understand the phenomenon completely.

Downwash and Wake Behind Plain and Flapped Aerofoils. (A. Silverstein, S. Katzoff and W. K. Bullivant, N.A.C.A. Report No. 65I, I939.) (67/16 U.S.A.)

Extensive experimental measurements have been made of the downwash angles and the wake characteristics behind aerofoils with and without flaps and the data have been analysed and correlated with the theory. A detailed study was made of the errors involved in applying lifting-line theory, such as the effects of a finite wing chord, the rolling-up of the trailing vortex sheet, and the wake.

The downwash angles, as computed from the theoretical span load distribution by means of the Bint-Savart equation, were found to be in satisfactory agreement with the experimental results. The rolling-up of the trailing vortex sheet may be neglected, but the vertical displacement of the vortex sheet requires consideration.

By the use of a theoretical treatment indicated by Prandtl, it has been possible to generalise the available experimental results so that predictions can be made 
of the important wake parameters in terms of the distance behind the aerofoil trailing edge and the profile drag coefficient.

The method of application of the theory to design and the satisfactory agreement between predicted and experimental results when applied to an aeroplane are demonstrated.

Comparison of Profile Drag and Boundary Layer Measurements Obtained in Flight and in the Full-Scale Wind Tunnel. (H. J. Goett and J. Bicknell, N.A.C.A. Tech. Note No. 693, March, 1939.) (67/17 U.S.A.)

The effect of the existing turbulence in the full-scale tunnel was determined from measurements of the profile drag of an $\mathrm{N}-22$ section by the momentum method under corresponding conditions in flight and in the tunnel. The transition point location on the upper surface of the aerofoil was also determined from velocity surveys in the boundary layer. The measurements were made at section lift coefficients from 0.480 to 0.635 with a range of Reynolds numbers from $3,900,000$ to $4,600,000$.

The results show that the end of transition occurs at approximately the same point on the aerofoil in flight and in the tunnel. The transition region was somewhat broader in the tunnel and started farther forward than in flight. The laminar profiles in the tunnel had some characteristics of transition profiles and had a much steeper slope, $\partial u / \partial y$, near the surface than did the laminar profiles obtained in flight. These differences, however, caused an increase of only $0.000 \mathrm{I}$ in the profile drag coefficients, as determined by the momentum method.

The Effect of Some Common Surface Irregularities on Wing Drag. (M. J. Hood, N.A.C.A. Tech. Note No. 695, March, 1939.) (67/18 U.S.A.)

The N.A.C.A. has conducted tests to provide more complete data than were previously available for estimating the effects of common surface irregularities on wing drag. The irregularities investigated included : Brazier head and countersunk rivets, spot welds, several types of sheet metal joints, and surface roughness. Tests were also conducted to determine the over-all effect of manufacturing irregularities incidental to riveted aluminium alloy and to spot-welded stainless steel construction. The tests were made in the 8-foot high speed wind tunnel at Reynolds numbers up to $18,000,000$.

\section{Conclusions.}

1. Rivets at $\frac{3}{4}$ inch pitch in 13 spanwise rows on each surface of an aerofoil at 5 -foot chord increased the drag from 6 per cent. for countersunk rivets to 27 per cent. for $\frac{3}{32}$ inch brazier head rivets. About yo per cent. of these drag increments were due to the rivets on the forward 30 per cent. of the aerofoil.

2. Lapped joints, arranged six on each surface, increased the drag of the aerofoil from 4 per cent. for joggled laps to 9 per cent. for conventional laps.

3. Surface roughness may cause serious increases in drag; for example, the roughness due to spray painting increased the drag i 4 per cent. and roughness of 0.0013 inch grain size increased the drag 42 per cent.

4. Manufacturing irregularities increased the drag of a typical wing 8 per cent. of the smooth wing drag over and above the increments due to the rivets and lapped joints.

Investigation of the Lift Distribution Over the Separate Wings of a Biplane. (D. Kuchemann, L.F.F., Vol. 15, No. Io-I I, Ioth October, 1938, pp. 543-5. Available as Translation T.M. 889.) (67/19 U.S.A.)

An investigation is made of the mutual interference of the wings of a biplane under the general assumption that each wing may be replaced by a vortex system of the type given by the Prandtl wing theory. The additional velocities induced at each wing by the presence of the other are determined by the Bivot-Savart law 
and converted into an equivalent change in angle of attack, the effect being that of an additional twist given to the wings in changing their lift distributions. The lift distributions computed in this manner for several aeroplane types are compared with the results of measurement.

Propulsion and Resistance. (W. Schmeidler, Z.A.M.M., Vol. 19, No. 2, April, 1939, pp. 65-86.) (67/20 Germany.)

The author considers the flow phenomena accompanying the periodic motion of a wing in an airstream, paying particular attention to the calculation of propulsion and resistance. The investigation differs from previous work on this subject in that general expressions are obtained depending essentially on the periodical variation of the distribution of circulation about the wing.

Taking first the two-dimensional case, it is shown that a periodic variation in the distribution of the circulation produces in all cases a positive mean resistance, but that the ratio of propulsion to resistance (for horizontal flight at a given velocity and frequency) can be made as large as required by having a sufficiently flexible wing.

In the three-dimensional case, buth the transverse and longitudinal vortices shed by the wing are considered. The distribution of circulation round the wing is assumed to be that of a series of bound vortex filaments in the direction of the span, the circulation vanishing at the end of the filament. The general equations are simplified by assuming that $\gamma b / \mu$ is small, $\gamma=$ frequency, $b=$ span, $\mu=$ incident air speed. For a given span distribution of the circulation the chord distribution giving maximum net propulsion is calculated.

Variation in Velocity Profile with Change in Surface Roughness of Boundary. (W. Jacobs, Z.A.M.M., Vol. 19, No. 2, April, 1939, pp. 87-100.) (67/21 Germany.)

The phenomena accompanying fully estabished turbulent flow along a boundary of known roughness may be considered as being now understood. Expressions have been obtained for smooth and rough tubes and channels for the velocity distribution, resistance, exchange in impulse and the mixing path. If the surface roughness undergoes a change a new velocity profile has to be formed and this transition region has so far been investigated only theoretically, making certain simplifying assumptions. The author has carried out experiments over this region and utilised the results to establish a new method for calculating the velocity distribution over the transition section of a channel when changing from smooth to rough and vice-versa, provided the shear stress at the wall under conditions of fully established flow is known. The predictions have been confirmed by further experiments.

Flow Phenomena at Nozzles and Orifices. (P. Jordan, Forschung, Vol. 1o, No. 2, March-April, 1939, pp. 88-92.) (67/22 Germany.)

The experiments were carried out in a rectangular water channel of special design, the flow being rendered visible by the introduction of a special dye. This colouring matter was either introduced into the stream or emitted from a series of holes on the surface of the nozzle or orifice plate (two-dimensional mode's only).

The Reynolds numbers ranged from $10^{4}$ to $10^{5}$ and photographs are given showing typical boundary layer phenomena. It is hoped by further studies of this kind to clear up certain anomalies noted in the calibration of nozzles and orifices and thus increase the accuracy of flow measurements.

The Design of Jet Pumps (Injectors and Ejectors). (G. Flugel, Forschungsheft, No. 395, March-April, I939, pp. I-21.) (67/23 Germany.)

The theory of jet pumps is still rather incomplete and relatively little has been published so far. Successful designs have been developed by trial and error and 
information obtained in this way is naturally guarded by the various firms concerned.

The author shows that by applying both the energy and impulse theorems, the optimum dimension of the collector throat and best shape of intake can be determined approximately in a relatively simple manner.

The necessary length of the collector follows from Prandtl's turbulent mixing theory.

The calculations are carried out for the mixing of similar and dissimilar fluids.

\section{The Application of Electrical Equipment to Aircraft. (O. F. Olsen, J.S.A.E., Vol. 44, No. 4, April, 1939), p. 12.) (67/24 U.S.A.)}

The author surveys the fundamental considerations involved in the application of electrical equipment to aircraft. Factors are reviewed that establish the rating of electrical equipment. Important limitations due to materials used in the construction of apparatus are noted, and how they may be influenced by some of the new developments. The adaptability of standard industrial equipment to aircraft requirements is evaluated, with the modifications desired. The range of electrical characteristics is reviewed, with the underlying characteristics that influence their selection. The more important equipment and some of the relatively new devices are explained and their application characteristics noted. The requirements for the co-ordination of equipment into a complete, reliable, flexible, and adequate system are set forth.

Feathering Propellers in Air Line Operation. (M. G. Beard and E. W. Fuller, J.S.A.E., Vol. 44, No. 4, April, 1939, pp. 20-1.) (67/25 U.S.A.)

In this paper the full feathering principle is explained in two distinct propeller designs.

Performance figures are given for twin-engined air transport planes with and without feathering propellers, and the importance of the feathering propeller in the operation of four-engined aeroplanes and its beneficial effect upon twin and triple engine performance is pointed out. Propeller icing, pertinent flight test data, the value of the feathering propeller in studying propeller ice in flight, and future propeller design trends, also are discussed by the authors.

\section{A Report of Studies and Tests to Decrease Aircraft Fire Hazard. (A. W.} Dallas, J.S.A.E., Vol. 44, No. 4, April, 1939, p. 21.) (67/26 U.S.A.)

From the results of tests on the ignition of petrol and fuel oils in an airstream, the author concludes that fuel may be dumped safely from an aeroplane in flight, provided that it is discharged clear of the aeroplane structure. In his paper he reports the activities of the Technical Development Division of the Civil Aeronautics Authority in connection with aircraft fire hazards.

A comprehensive test programme is now being formulated by the Civil Aeronautic Authority, U.S.A., for the purpose of determining means of safeguarding aircraft from the dangers associated with power plant fires. These tests will be conducted on a full-scale nacelle and stub wing, complete with engine, propeller, and accessories. The engine will be operated, and the whole set-up placed in an air stream during the tests to simulate actual flight conditions. Tests will be made on fire detectors and fire extinguishers, and also on various materials and accessories, to determine suitable designs which will present the highest degree of safety from power plant fires.

Résumé of Air Load Data on Slats and Flaps. (C. J. Wenzinger and F. M. Rogallo, N.A.C.A. Tech. Note No. 690, March, 1939.) (67/27 U.S.A.)

A résumé of the generally available test data regarding air loads on slats and flaps is presented and data obtained up to the end of 1938 are included. The data are given in the form of N.A.C.A. standard coefficients of air forces and moments 
on the lift increasing device and, when available, the aerodynamic characteristics of the combined wing and high lift device are included. Slats of the Handley Page type, fixed auxiliary aerofoils, and flaps of several different types are covered.

Some Fundamental Considerations in Regard to the Use of Power in Landing an Aeroplane. (W. S. Diehl, N.A.C.A. Tech. Note No. 692, March, 1939.) (67/28 U.S.A.)

This note is concerned with the effect of power on landing speed and apparent maximum lift coefficient. It is shown that when secondary effects are neglected, the maximum available increase in lift due to power is equal to the thrust being developed. If the increase in lift due to power is expressed in coefficient form, very high values may be shown under conditions which, on analysis, are found to be wholly impracticable in flight.

Propeller Tests to Determine the Effect of Number of Blades at Tuo Typical Solidities. (E. P. Lesley, N.A.C.A. Tech. Note No. 698, April, 1939.) $(67 / 29$ U.S.A.)

Propellers with equal total blade area, but with different numbers of blades, were tested.

The tests show generally that, for equal total blade area, propellers with the larger number of blades absorb the greater power and, provided hubs have equal drag, develop the higher efficiency.

It is shown that the differences found are in agreement, qualitatively, with what might be predicted from simple blade element theory.

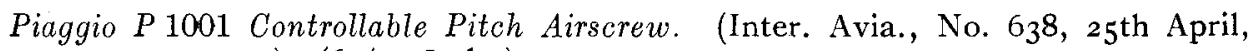
I939, p. 7.) (67/30 Italy.)

Piaggio have produced a new controllable pitch airscrew, type $\mathrm{P}$ Ioor, which differs from earlier Piaggio airscrews (Inter. Avia., No. 480 ) by a number of major improvements. The P IooI airscrew permits the control of the blade pitch within any range up to the feathering position and is provided, furthermore, with an automatic constant speed control allowing any desired speed to be selected. The pitch changing energy is supplied by the engine torque, the control instrument operates electrically (current consumption io watts). The change to feathering position may be effected either mechanically, hydraulically or pneu. matically. The new Piaggio airscrew may be fitted to any engine without necessitating any modifications to the latter. The operation of the pitch control installation by the pilot is very simple; it is sufficient to move a small lever on the control instrument to the desired blade pitch or to switch on the speed control.

\section{Messerschmitt Controllable Pitch Airscrew V.P. 7. (Inter. Avia., No. 639, 28/4/39, pp. 7-8.) (67/3 I Germany.)}

The Messerschmitt A.G. of Augsburg has developed a controllable pitch airscrew, type V.P. 7, for special use on the Me. 108 "Taifun" high speed touring aeroplane. (Argus As ro engine of 200-240 h.p.) This airscrew is of extremely low weight and of very simple design; changes in the blade pitch are effected manually by mechanical means.

\section{Construction Details.}

The Messerschmitt V.P. 7 controllable pitch airscrew consists of two-coated light wood blades, patent Schwarz, with standardised Schwarz blade mounting. The steel hub is undivided and connected to the shaft by Hirth teething and a differential screw. Located on the hub shaft is a control ring, displaceable longitudinally and connected to the blade roots by short levers, thus making pitch changes possible. The displacement of the control ring is effected by a control traverse with internal Radiax ball bearings, mounted on gimballs on the engine 
casing and operating in the manner of a lever. This control traverse is operated manually by the pilot (crank) via a rod system with Werner joints and a control spindle on the hub; the spindle is self-locking. Connected to the hand crank, which is arranged on the instrument board, is an indicating device on which the position for " take-off " and "cruising" are specially marked. All parts of the airscrew are exchangeable. The hub assembly includes a quickly dismantling spinner. Airscrew diameter $9^{2 \frac{1}{2}}$ in. $(2.55 \mathrm{~m}$.), pitch change ro deg., plus 2 deg. reserve, weight $82.5 \mathrm{lb}$. $(37.5 \mathrm{~kg}$.$) , which is only about 20 \mathrm{~kg}$. (44.1b.) more than the weight of a fixed airscrew.

A Discussion of Propeller Efficiency. (H. M. McCoy, J. Aeron. Sci., Vol. 6, No. 6, April, I939, pp. 227-234.) (67/32 U.S.A.)

A certain amount of confusion arises, due to the fact that propeller efficiency is defined in various ways.

(I) The "isolated" efficiency $=T V /(2 \pi n Q)$ and refers to the propeller alone working in free air.

(2) The " apparent " efficiency refers to the same ratio, the propeller working close to a body. No evaluation is made of the effect of the slipstream on the body drag.

(3) The "net" efficiency is defined as $V(T-R) /(2 \pi n Q) . T$ and $R$ represent the propeller thrust and body drag respectively, each being measured in the presence of the other. The combination of propeller and body is regarded as a propulsive unit.

(4) The "propulsive" efficiency $=V\left[T-\left(R-R_{\mathrm{o}}\right)\right] /(2 \pi n Q)$ where $R_{\mathrm{o}}=$ drag of body without propeller.

$\left(R-R_{\mathrm{o}}\right)=$ increase in body drag due to slipstream.

$T=$ propeller thrust measured in presence of body.

$\left(R-R_{0}\right)$ is usually negative for cowled radial engines, i.e., the slipstream decreases body drag.

The author presents a method of utilising " net" efficiencies, to check level flight performance.

Attention is called to the great improvement in performance that can be expected by enclosing the engines within the aeroplane or wing structure and driving the propellers by extension shafts.

Experiments with "Contact Lights" to Assist Fog Landings. (Inter. Avia., No. $640,2 / 5 / 39$, p. 8.) (67/33 Great Britain.)

The lights are disposed in two parallel lines $6_{5}$ yards apart along the line of approach indicated by the wireless beacon.

Outside the aerodrome boundary are placed six approach lights, 40 yards apart (sodium lights on the right and mercury lights on the left). Inside the aerodrome boundary are two strips of green lights (270 yards) followed by white (450 yards) and red ( 360 yards). These lights are set flush with the ground, the approach light being, however, tilted at an angle of $20^{\circ}$ towards the incoming aircraft.

The flush lights are covered with glass lenses, capable of withstanding loads of the order of ro tons per square foot.

The. Manufacture of Airscrews. (Machinery, 27/4/39; pp. 93-103, p. I. Metropolitan Vickers Technical News Bulletin, No. $659,5 / 5 / 39$, p. I.) (67/34 Great Britain.)

This article describes the design and machining operations entailed in the manufacture of the Rotol constant speed hydraulically operated airscrew. The airscrew, which is of the three-bladed type, is controlled by a constant speed governor, so that the angular setting of the blades is fixed automatically during 
Hight by the position of the speed control lever; this acts direct on the governor mechanism and not on the engine throttle. A detailed explanation of the operating and reversing mechanism is given, and the production methods applied to the main components are outlined.

Illustrated with four diagrams, 20 photographs and one table.

The Unit Power Plant (Rapidly Interchangeable Power Plant for Aircruft). (W. Jellinghaus, Luftwissen, Vol. 6, No. I, January, I939, pp. 27-29. Available as Air Ministry Translation.) (67/35 Germany.)

The author describes the power installation developed by the Junkers works for the BMW. $132 \mathrm{H}$ (radial) and Jumo 2 I I A (in-line $\mathrm{V}$ ) engines.

In the former case the oil radiator and oil tank are placed inside the unit.

For the $V$ engine, circular nose radiators, both for water and oil, are fitted. The power plant is attached by means of four lock nuts to the fireproof bulkhead. Provision is made for 22 pipes, six control rods and cables, and four electrical multiplied connections in the bulkhead.

The pipe connections are of the self-sealing type and special bayonet joints are provided for the control rods and cables. A special connector (not described) is fitted to the exhaust and hot air pipes which pass through the bulkhead.

It is claimed that an interchange of the power plant can be carried out in half an hour.

It is interesting to note that provision is made on the bulkhead for a hot air delivery pipe for de-icing nose of wing. (This air is warmed by the exhaust pipe and is drawn through the wing by the proper choice of discharge orifices near the trailing edge, see Air Ministry Translation No. 535.)

Permissible Amplitudes of Torsional Vibrations in Aircraft Engines. (F. Masi, J.S.A.E., Vol. 44, No. 4, April, I939, p. Ir.) (67/36 U.S.A.)

Actual computation of the vibratory crankshaft stresses, although a laborious process with many difficulties, should offer the best chance for an intelligent evaluation of the crankshaft torsional vibration characteristics in aircraft engines and of whether the amplitudes are dangerous or within safe limits. In a discussion of various methods used, their relative merits, and allied problems, the author shows that the simple expediency of using fixed allowable amplitude limits, for certain classes of engines, determined from experience, is likely to lead to crroneous conclusions.

A novel method, which has been used on numerous engines by the Naval Bureau of Aeronautics, is suggested. It consists in determining the twist of the crankshaft with the application of rated engine torque and basing the allowable vibration amplitude on the amount of the twist. This method lends itself to rapid routine check of a variety of engines and gives reliable data for conventional designs.

Present-Day Problems in Accessory Drive. (R. P. Lansing, J.S.A.E., Vol. 44 , No. 4, April, 1939, pp. 12.) (67/37 U.S.A.)

The paper brings out the numerous problems found in the design of accessory power supplies for the larger aeroplanes and the involvements incident to such design, without attempting to forecast their solutions. These problems are primarily the result of the. requirements of the long-range plane. It is shown that, in these planes, controls other than flight controls require substantial power to operate them. Landing gears which must be operated are of substantial weight and size, and require considerable power, although in smaller amounts. Radio has many ramifications, such as communications, beam flying, orientation, blind Hying, and emergency equipment, all of which necessitate a large increase in power. Pressure cabins also add to the demands for auxiliary power. 
Topics discussed are choice of generator drive; accessory drives from main engines; drive by accessory engines; and actuation by electric motor, hydraulics, air pressure, and vacuum.

Fuel Economy Possibilities of the Otto Cycle Aircraft Engine. (D. S. Hersey, J.S.A.E., Vol. 44, No. 4, April, 1939, pp. 20.) (67/38 U.S.A.)

Economy of present-day aircraft engines can be improved merely by advancing to spark advance control. The reduction of cruising in-take charge temperatures by the employment of multi-speed superchargers with adequate charge intercooling, also should permit the early use of slightly higher compression ratios.

'T he author suggests that an engine developed primarily for economy should be able to develop its maximum cruising output at sea level when unboosted and operated at moderate speeds, thus permitting higher compression ratios with further improvement in economy.

The paper outlines the general and economy requirements of existing aircraft engines, and the economy effects of various operating conditions. The factors that affect detonation at both high output and economy conditions, as well as the compromises necessary to avoid detonation, are considered in some detail.

Present Prospects for Use of Safety Fuels in Spark Ignition Engines. (F. C. Mock, J.S.A.E., Vol. 44, No. 4, April, 1939, pp. 21-2.) (67/39 U.S.A.)

Recent developments in fuel refining have developed new safety fuels, with a flash point of about $105^{\circ} \mathrm{F}$, distillation range $375-475^{\circ} \mathrm{F}$. and about 87 octane rating.

Three methods of fuel feed are discussed:-

(I) Injection into the cylinder.

(2) ", ", intake pipe.

(3) , , , supercharger.

Detailed problems discussed cover:--

(I) Injection equipment.

(2) Change in engine and cylinder required.

(3) Fuel/air metering and power control.

(4) Starting.

(5) Installation.

It appears that over 60 per cent. of the Cierman aircraft engines are now using fuel injection. Quite apart from better distribution, fuel injection equipment can burn a wider range of fuels and this may be another reason for the German choice.

Characteristics of Magnetically Actuated Fuel Injection Valve. (C. J. Vogt and T. A. Rogers, Autom. Ind., Vol. 8o, No. 16, 22/4/39, pp. 530-6.) (67/40 U.S.A.)

The magnetically actuated spray valve offers a means of accurately controlling the quantity of fuel injected per cycle. It will accurately meter smaller quantities than is possible with any mechanical system. Successive sprays are reproducible, which is a large factor in smooth engine operation. Control of the character of the spray by simple changes in the electrical circuit has great possibilities.

Governing of injection delay offers no complex problems, since the system is independent of the dynamics of the pump and the fuel column.

Effect of Air Movement on Combustion Rates in Spark Ignition Engines. (A. M. Rothrock, J. Aeron. Sci., Vol. 6, No. 6, April, 1939, pp. 273-277.) (67/4I U.S.A.)

In the case of spark ignition engines, the air movement is produced during the induction stroke and persists to a considerable degree through the compression stroke and in some cases through the expansion stroke. 
The air movement may be of the swirl type (regular rotation) or turbulent (irregular movement on either a large or small scale).

The air movement produced by changes in the masking of the inlet valve was studied experimentally both under motoring and firing conditions. In the former case the engine was provided with a glass cylinder and the air currents (rendered visible by means of small feathers) were photographed (2,000 frames a second).

The firing experiments were carried out on a different engine (same shape combustion head) fitted with a glass window in the head and using the Schlieren method.

The principal conclusion reached is that an increase in the velocity of the incoming air does not necessarily increase the rate of combustion. Valve arrangements giving maximum turbulence generally produced longer combustion times than arrangements producing a mixture of swirl and turbulence.

It thus appears that the well known reduction of combustion time with speed of engine operation cannot be accounted for solely by an increase in turbulence.

\section{Stress Analysis for Leading Edge Wing Spars. (J. S. Newell, J.S.A.E., Vol. 44, No. 4, April, I939, p. 22.) (67/42 U.S.A.)}

Wing beams having a single shear web, located at about 30 per cent. of the wing chord, plus a stress carrying sheet running around the leading edge, are in most cases unsymmetrical sections and should be analysed as such. Because of the thinness of the shear-carrying elements, special care is required in determining the distribution of the shear stresses around the cross-section.

The internal shear stresses acting upon each unit area in the cross-section are shown to result in forces that tend to twist the beam, unless there is coincidence of the lines of action of the resultants of the internal shear forces and of the external forces producing shear on the cross-section. For this reason it is imperative that means be provided for determining the " shear centre " or " centre of twist " of the beam so that the magnitudes of such torsional couples may be evaluated. The author provides these means in the form of formula, and presents an example to illustrate their use.

Physical Properties of Synthetic Resin Materials. (M. Fishbein, N.A.C.A. Tech. Note No. 694, March, I939.) (67/43 U.S.A.)

A study was made to determine the physical properties of synthetic resins having paper, canvas, and linen reinforcements, and of laminated wood impregnated with a resin varnish.

The results show that commercial resins have moduli of elasticity that are too low for structural considerations. Nevertheless, plastics exist that have favourable mechanical properties and, with further development, it should be possible to produce resin products that compare favourably with the light metal alloys.

The results obtained from tests on Compound $\mathrm{I}, 840$, resin impregnated wood, show that this material can stand on its own merit by virtue of a compressive strength four times that of the natural wood. This increase in compressive strength was accomplished with an increase of density to a value slightly below three times the normal value and corrected one of the most serious defects of the natural product.

\section{Conclusions.}

The future of plastics and wood impregnated with resins depends to a great extent upon the impetus which the aircraft industry, in co-operation with the manufacturers of these products, is willing to give to experiments and to the development of these materials from considerations of improved mechanical strength. For plastics to be active competitors of the present light alloys, they must be improved to the point where-they have well-defined physical properties and, in the case of wood, the heterogeneous character of the material must be changed to one that approaches homogeneity. 
Torsional Stability of Aluminium Alloy Seamless Tubing. (R. L. Moore and D. A. Paul, N.A.C.A. Tech. Note No. 696, March, 1939.) (67/44 U.S.A.)

The results of these torsion tests on several different sizes of $5^{\mathrm{I}}$ ST seamless round tubing may be summarised as follows:-

I. The maximum shearing stresses developed in the tubes having $D / t$ ratios of 77,104 and I 39 , for lengths equal to the diameter, were computed to be $2 \mathrm{I}, 800, \mathrm{I} 9,200$ and $\mathrm{I} 8,400$ pounds per square inch, respectively. For lengths of 40 times the diameter in the same size of tubing, the corresponding maximum shearing stresses were $10,400,7,500$ and 4,800 pounds per square inch, respectively.

2. Elastic instability failures were apparently obtained in all the tubes tested having lengths greater than two to six times the diameter. For shorter lengths, failures resulted from a combination of yielding of the material in shear and buckling.

3. The torsional strengths developed in the tubes that failed elastically were, in most cases, within Io per cent. of the values indicated by the theories of Donnell, Timoskenko and Sturm, assuming a condition of simply supported ends.

4. Sturm's theory indicated critical shearing strengths below those of Donnell in all cases, but in close agreement with those of Timoshenko in the long-tube range. The test values were found to lie for the most part within the limits indicated by the different theories.

5. Although some end fixity was undoubtedly obtained in the tests, the unknown degree to which this effect was compensated for by out-of-roundness in the tubes and eccentricities of loading makes it difficult to differentiate between the accuracy of the different theories.

The Frequency of Torsional Vibration on a Tapered Beam. (R. P. Coleman, N.A.C.A. Tech. Note No. 697, March, I939.) (67/45 U.S.A.)

A solution for the equation of torsional vibration of tapered beams has been found in terms of Bessel functions for beams satisfying the following conditions : (a) The cross sections along the span are similar in shape; and (b) the torsional stiffness of a section can be expressed as a power of a linear function of distance along the span. The method of applying the analysis to actual cases has been described. Charts are given from which numerical values can be immediately obtained for most cases of practical importance. The theoretical values of the frequency ratio have been experimentally checked on five beams having different amounts of taper.

Metal Sprayed Bearings. Their Use for High Speed Operations. (H. Shaw, Metal Industry, 14/4/39, pp. 415-8. Metropolitan Vickers Technical News Bulletin, No. $657,21 / 4 / 39$, p. I.) (67/46 Great Britain.)

Tests have been made on a wide range of bearing metals built up by metal spraying as against the same metals cast. The test pieces included sprayed metal from France, Germany and America. Friction and seizure load tests were run at speeds of $50, \mathrm{r}, 000$ and $3,000 \mathrm{ft} . / \mathrm{min}$. on babbit, and sprayed babbitt, using plain and graphited lubricating oils. A similar test on lead bronze bearings was performed, and the results indicated that the use of sprayed metal gave lower friction and higher seizure loads. Other materials including cadmium-nickel, cadmium-nickel-silver, and cadmium-silver-copper were tested especially with respect to their tendency to crack under impulsive loading. The influence of colloidal graphite is discussed.

Illustrated with two tables and two graphs. 
The Elastic Theory of Wood Failure. (C. B. Norris, Trans. A.S.M.E., Vol. 6I, No. 3, April, 1939, pp. 259-26r.) (67/47 U.S.A.)

This paper deals with various theories advanced for the failure of wood. The formulæ developed by Jacuby, Howe and Hankinson for expressing the crushing strength of wood are examined and their relative practical value indicated. Of the three the Hankinson formula, while being strictly empirical, agrees with experimental results better than the others. The author then proceeds to outline the steps of derivation of Hankinson's formula, applying the theory of failure advanced by Hencky. A second theory is analysed which also leads to Hankinson's formula. The author points out that the methods used in deriving Hankinson's formula are very approximate, but that such a formula is better than none.

Fully Automatic Riveting in Light Metal Aircraft Construction. (W. Pleines, Inter. Avia., No. 638, 25th April, 1939, pp. I-3, and Inter. Avia., No. 637, 2 Ist April, 1939, pp. I-3.) (67/48 Germany.)

After pointing out that welded joints are not as strong as rivets, the author describes a new automatic riveting machine originally developed by the Henschel Aircraft Works and which is now on sale.

I. During the process of making a rivet joint the work was not displaced; all operations, drilling, countersinking (with cutting detachment), insertion of rivet, possibly dimpling of the hole borders, driving and heading of rivet, are effected automatically by one single engagement of the machine; they take place in a vertical axis to enable also curved parts to be machine riveted.

2. The holes are drilled in order to obtain maximum smoothness of the hole walls (advantage over stamping, elimination of hair cracks in the light alloys which, as is well known, are particularly liable to notching) and, eventually, to countersink with removal of chips simultaneously with the drilling by means of special countersink drills. The chips generated on both sides of the work, i.e., the entry and exit sides of the drill, are removed by compressed air.

Arc Welding with Special Reference to the Welding of High Alloy Steels and Non-Ferrous Metals. (F. Womaczka, Elektrotechnik und-Maschinenbau, 31/3/39, pp. I78-I89. Metropolitan Vickers Tech. News Bulletin, No. 658, 28/4/39, p. 8.) (67/49 Germany.)

The author discusses those special problems of the technique of arc welding which are set by the nature of the material. In particular he considers the welding of thin sheet, of high carbon steels and steels which are difficult to weld, of high alloy steels, and of non-ferrous metals, including aluminium and copper as well as their chief alloys. He gives a number of tables, for example, one showing the thicknesses of sheet which can be welded by various types of joint, another giving the strength properties of butt welds on $12 \mathrm{~mm}$. sheet; two others give figures for notch impact strength and fatigue bending strength for 12 and $6 \mathrm{~mm}$. sheet. Illustrated with 14 photographs.

Riveting Machines and Light Alloy Rivets. (C. Harris, Light Metals, Vol. 2, No. I 5, April, 1939, p. 133.) (67/50 Great Britain.)

After dealing with a representative type of solid riveter the author discusses the advantages of employing tubular or semi-tubular rivets for certain kinds of work. Although much more expensive, the tubular rivet possesses many advantages mainly due to the greater ease of control during setting. The elimination of excess metal in the rivet shank reduces the relatively heavy working required when heading a solid rivet.

No diminution of the shear strength is occasioned, the tubular type ensuring a perfectly tight fit in the hole. 
Examples of high speed rivet setting machines for tubular rivets are described. It is stated that the setting of the rivets is rather quicker than spot welding.

The Use of Symmetric and Anti-Symmetric Loadings. (J. S. Newell, J. Aeron. Sci., Vol. 6, No. 6, April, I939, pp. 235-239.) (67/5 I U.S.A.)

The stressing of statistically indeterminate structure becomes relatively easy if the structure is symmetrical and the load applied symmetrically. Now the advantage of symmetry may be had on any symmetrical structure, by substituting two or more equivalent force systems for the original unsymmetrical loading.

In the usual case, two systems suffice. One system has all forces and reactions symmetrically disposed about the plane of symmetry, the second has them arranged anti-symmetrically, i.e., force having components acting towards plane of symmetry or upwards on the right, have counterparts in the opposite direction on the left, etc.

Under such loadings relationships exist involving not only forces and moments, but also slopes and deflections. As a result I 2 general equations of conditions can be established which are very useful in the rapid analysis of the structure.

The author illustrates the application of the method by means of two worked out examples.

\section{Measurement of Stiffener Stresses and Effective Widths in Stiffened Panels.}

(H. B. Dickinson and J. R. Fischel, J. Aeron. Sci., Vol. 6, No. 6, April, 1939, pp. 249-54.) (67/52 U.S.A.)

In the design of a stressed skin metal aeroplane it is essential that correct stiffener stresses and effective widths of skin acting with the stiffener be known in order to ensure that fictitious margins of safety in wing and fuselage analyses are not shown. In this paper the problem of determining these stresses and effective widths is discussed and some experimental results from Lockheed tests are presented. An experimental method is described which makes possible the accurate determination of these quantities, employing extensometer strain data interpreted by means of a compression stress-strain curve for the stiffener.

The Application of Thermostatic Bimetals. (P. A. Morgan, Mech. World, 7/4/39, pp. 339-4I. Metropolitan Vickers Tech. News Bulletin, No. 656, I $4 / 4 / 39$, p. I.) $(67 / 53$ U.S.A. $)$

After describing the various forms in which thermostatic bimetallic strips are produced, and their application to apparatus of different types, it is shown that a thin strip produces a greater deflection than a thicker element, but develops less power to actuate any device depending on its movement. The power can be increased by using a wider strip and the deflection by increasing the length. The design of a suitable element is a compromise between these factors. Examples are given of the use of bimetallic elements, applications mentioned including. a vertical stem type dial thermometer a thermostatic mixing valve, automatic reset and manual reset motor protection thermostats, and a thermostatically controlled gas jet.

Illustrated with six photographs.

Air Line Power Control with a Torque Meter. (W. G. Lundquist, J.S.A.E., Vol. 44, No. 4, April, 1939, p. 20.). (67/54 U.S.A.)

In this paper the author presents an impartial discussion on the possible benefits to airline operators of using torque meters. He points out that the long-range operator is the only one who probably will realise any appreciable improvement in operating efficiency by the use of the torque meter, and even he must survey carefully his present operations to ascertain whether or not he already is operating so near to maximum efficiency that the application of the 
torque meter will not produce any benefits. The torque meter will add from Io to $5 \mathrm{olb}$, to an engine, including the indicating equipment.

The mechanical features of some current torque meter types are reviewed.

Correlation of Aircraft and Ground Station Altimeters. (R. D. Kelly and H. F. Salisbury, J. Aeron. Sci., Vol. 6, No. 6, April, I939, pp. 240-272.) (67/55 U.S.A.)

The errors treated by the author come under the following five headings:-

(I) Errors in the basic standard instrument (usually a mercury barometer).

(2) Errors in calibration, temperature, friction, balance, etc., of aircraft instruments.

(3) Personal errors.

(4) Installation errors.

(5) Incorrect or non-uniform ground station elevation.

In order to determine and control the actual existing spread of altimeter readings, a record is kept by United Air Lines for one day every month of the indications of the flight altimeter readings of planes located at a series of stations.

The Theory of Diaphragm Pressure Recorders. (A. Moller, Forschung, Vol. Io, No. 2, March-Apri1, 1939, pp. 80-87.) (67/56 Germany.)

The author considers the case of a thin circular diaphragm, clamped at the edges and undergoing a relatively large deflection when subjected to a pressure difference, one side of the diaphragm being sealed (capsule). Equations are developed for correlating the deflection with changes in the electrical capacity of the system and thus rendering an electrical method of recording possible.

The zero position of the membrane of a sealed capsule naturally depends on the atmospheric pressure, but this effect can be allowed for by having a double capsule, the second being in communication with the atmosphere.

The method of calibrating capsules of this type is described and examples of pressure records are given.

Diffraction and Refraction of a Horizontally Polarised Electro-Magnetic Wave Over a Spherical Earth. (M. C. Gray, Phil. Mag., Vol. 27, No. I83, April, 1939, pp. 421-436.) (67/57 Great Britain.)

Formulas are derived for the electro-magnetic field at a point on or above the surface of a spherical earth due to the presence of a vertical magnetic dipole. It is shown that the resultant field resembles that due to a vertical electric dipole above a spherical earth of low conductivity, and that in the magnetic case the values of the earth constants are of much less importance than in the electric. Curves are included showing the variation of the field with distance and height.

Improvements in the Lorenz Blind Landing System. (Inter. Avia., No. 639, $28 / 4 / 39$, p. 7.) $\left(67 / 5^{8}\right.$ Germany.)

Tests with an improved Lorenz glide-path installation have been conducted already in September, 1938 . These tests have now been resumed. It has been possible to improve considerably, by the use of the new installation, the blindlanding system employed, the following having been achieved by very simple means:-(I) the approach path now follows an entirely straight line from the beginning of the glide path (outer marker signal) down to the ground, as a result of which the machine is able to fly at a constant rate of descent. (2) The touching down point of the straight glide-path may be fixed at any desired distance from the airfield boundary. The glide-path installation operates with a Ico-watt transmitter (at present $35.8 \mathrm{mc}$.) which, seen from the homing transmitter, is located about $\mathrm{I}, 64 \mathrm{oft}$. (500 m.) laterally of the landing direction. A special receiver is 
provided in the aircraft which operates the available visual indicating device. A landing installation built for Fort Worth, Texas, by the Lorenz Company, now being installed, also makes use of the new glide-path principle though it works, corresponding to American requirements, on a frequency of about $94 \mathrm{mc}$.

Boiling Heat Transfer in Natural Convection Evaporators. (G. A. Atkin and W. H. McAdams, Ind. and Eng. Chem (Industrial Edition), Vol. 31, No. 4, April, 1939, pp. 487-91.) (67/59 U.S.A.)

I. With distilled water boiling at atmospheric pressure on horizontal nickelplated or chromium-plated tubes, the maximum flux was approximately the same (350,000 B.T.U. per hour per square foot) whether a single-tube or a sixty-tube apparatus was used. City water boiling on a scaled tube gave approximately the same maximum flux at a higher temperature difference.

2. Under similar conditions three paraffin alcohols (isopropyl, isobutyl, and n-butyl) gave only 30 per cent. as much maximum flux as distilled water, and required higher temperature differences.

3. At a given temperature difference, the effect of vacuum in reducing the flux is not so large in the range of high flux as that reported by others who used low flux.

4. Further work is needed to study the effects of a number of factors, such as pressure, nature of the surface, nature of the liquid, and variations in temperature with position on the tube.

\section{N.A.C.A. 24th Annual Report, 1938. (67/60 U.S.A.)}

During the period under review, the N.A.C.A. have issued 33 Reports, $5^{1}$ Notes and 39 'Tech. Memo. (Translations).

The total expenditure over the year amounted to approximately 2 million dollars, roughly half of which was utilised for personnel services.

Printing and binding accounted for 21,000 dollars.

The following are extracts from the concluding statement of the Report:-

Air power is primarily dependent not only upon numbers of aeroplanes, but the aeroplanes themselves must have performances at least equal to that of an enemy.

The fact that modern military aircraft requires frequent replacement by improved types brings forcibly to our attention the necessity of basing their design upon the best and most reliable data from research laboratories.

Unless our own laboratories keep pace, the U.S. cannot hope to compete with foreign nations in the development of either military or commercial aircraft.

The U.S. for a number of years have held undisputed leadership in the field of aeronautical research. At the present time that leadership is being challenged. Unless therefore we fully recognise the challenge and make provisions for extending the Committee's research facilities and for increasing the number of trained research personnel, the U.S. will definitely fall behind.

Methods of Clearing Aerodromes of Fog. (Les Ailes, Vol. 19, No. 931, 20/4/39, p. 8.) (67/6i France.)

Two possible methods exist for clearing a limited space of fog. One method is thermal, the other chemical.

The thermal method has so far only been tried in the form of heat (British tests with coke fires arranged along the contours of the landing ground).

As an alternative the author suggests fitting refrigerating plant below the runway and thus preventing the lower atmospheric layers from becoming saturated with water vapour.

It is claimed that a relative small decrease in air temperature will prevent the notorious " dissolving views" so dangerous during landing.

In the chemical method, calcium chloride is usually applied for absorbing the moisture vapour. In the scheme proposed by the author, the runway is in the 
form of a grid, the chemical being carried on a moving belt below the surface. The spent chemical is dehydrated in a special plant and stored for further use.

By applying both refrigeration and chemical water absorption, it should be possible to clear the fog up to an altitude of $30-40 \mathrm{~m}$.

Experiments on the I'hermal Radiation of Flames. (J. Werneburg, Forschung, Vol. Io, No. 2, March-April, 1939, pp. 6I-79.) (67/62 Germany.)

Measurements on the radiation of flames have so far been limited to fixed positions perpendicular to the flame axis, the radiation being assumed to be constant in all directions. The author amplified these results by investigating both the distribution in space as well as the variation in intensity over the surface of hydrogen and coal gas fiames. Whilst the radiation is not strictly equal in all directions, the total radiation can be calculated with sufficient accuracy from data based on normal emission.

The variation in the intensity of the radiation over the surface of the flame is appreciable, maximum values being usually obtained in the neighbourhood of the inner cone. It appears that in an ordinary welding process, the heat transmission by radiation may amount to between six and 25 per cent. of the total, depending on the scrubbing speed of the gas.

\section{LIST OF SELECTED TRANSLATIONS.}

Notk.-Applications for the supply of copies of translations mentioned below should be addressed to the Under-Secretary of State (R.T.P.), Berkeley Square House, W. I, and will be supplied, free of charge, as far as availability of stocks permit. Suggestions concerning new translations will be considered in relation to general interest and facilities available.

Lists of selected translations have appeared in this publication since September, $193^{8 .}$

TRANSLATION NUMBER

AND AUTHOR.

TITLE. AND JOURNAT.

Alrodynates and Hydrodyamics.

866 Frankl, F. ... ... Turbulent Friction in the Boundary Layer of a Flat Voishel, V. ... ... Plate in a Two-Dimensional Flow of Compressible Gas at High Speeds. (Trans. C.A.H.I. Moscow Report No. 321, 1937.)

868 Kiel, G. $\quad \ldots \quad \ldots$ The Measurement of True (Undisturbed) Static and Dynamic Pressures in Flight. (L.F.F., Vol. 15, No. 12, 20/1 2/38, pp. 583-97.)

870 Flugge-Lotz, I. ... Summarised Report on Measurement of Downwash Kuchemann, D. ... with and without Slipstream. (Jahrbuch der deutschen Luftfahrtforschung, Vol. 1, 1938, pp. 17 2-93.)

887 Stsielard, K. S. ... Measurement of the Drag of Wing Profiles in the C.A.H.I. High Speed Wind Tunnel. (Trans. All-Union Conference on High Speed Aircraft, Moscow, 1936, pp. 92-7.)

\section{Aircraft.}

874 Voigt, H. ... ... Further Experiments on Wing Vibrations. (Jahrbuch der deutschen Luftfahrtforschung, I938, Vol. I, pp. 249-58.)

882 Ritter, E. ... ... Collaboration Between the Aircraft Designer and the Production Engineer. (Jahrbuch der deutschen Luftfahrtforschung, 1938, Vol. I, pp. $4^{82-90 .)}$ 